\title{
Caspase-7: a critical mediator of optic nerve injury-induced retinal ganglion cell death
}

\author{
Shreyasi Choudhury ${ }^{1,2,3}$, Yang Liu ${ }^{1,2}$, Abbot F. Clark ${ }^{1,3}$ and lok-Hou Pang ${ }^{1,2^{*}}$
}

\begin{abstract}
Background: Axonal injury of the optic nerve $(\mathrm{ON})$ is involved in various ocular diseases, such as glaucoma and traumatic optic neuropathy, which leads to apoptotic death of retinal ganglion cells (RGCs) and loss of vision. Caspases have been implicated in RGC pathogenesis. However, the role of caspase-7, a functionally unique caspase, in ON injury and RGC apoptosis has not been reported previously. The purpose of this study is to evaluate the role of caspase-7 in ON injury-induced RGC apoptosis.

Results: C57BL/6 (wildtype, WT) and caspase-7 knockout (CaspT ${ }^{-1}$ ) mice were used. We show that ON crush activated caspase-7 and calpain-1, an upstream activator of caspase-7, in mouse RGCs, as well as hydrolysis of kinectin and co-chaperone P23, specific substrates of caspase-7. ON crush caused a progressive loss of RGCs to 28 days after injury. Knockout of caspase-7 partially and significantly protected against the ON injury-induced RGC loss; RGC density at 28 days post ON crush in Casp7 $7^{--}$mice was approximately twice of that in WT ON injured retinas. Consistent with changes in RGC counts, spectral-domain optical coherence tomography analysis revealed that ON crush significantly reduced the in vivo thickness of the ganglion cell complex layer (including ganglion cell layer, nerve fiber layer, and inner plexiform layer) in the retina. The ON crush-induced thinning of retinal layer was significantly ameliorated in Casp $7^{-1-}$ mice when compared to WT mice. Moreover, electroretinography analysis demonstrated a decline in the positive component of scotopic threshold response amplitude in ON crushed eyes of the WT mice, whereas this RGC functional response was significantly higher in Casp $7^{-/-}$mice at 28 days post injury.

Conclusion: Altogether, our findings indicate that caspase-7 plays a critical role in ON injury-induced RGC death, and inhibition of caspase-7 activity may be a novel therapeutic strategy for glaucoma and other neurodegenerative diseases of the retina.
\end{abstract}

Keywords: Caspase-7, Optic nerve injury, Retinal ganglion cell, Neuroprotection

\section{Background}

Axonal injuries occur in a wide range of CNS disorders. They contribute to neuronal damage in diseases and trauma of the human brain and spinal cord. Similarly, injury to the optic nerve (ON), an extension of the CNS, is associated with various ocular diseases and abnormalities, such as glaucoma, traumatic optic neuropathy, ischemic optic neuropathy, and compressive optic neuropathy. In humans, there are approximately 1.2 million axons in

\footnotetext{
* Correspondence: iok-hou.pang@unthsc.edu

${ }^{1}$ North Texas Eye Research Institute, University of North Texas Health Science Center, 3500 Camp Bowie Blvd, Fort Worth, TX 76107, USA

${ }^{2}$ Pharmaceutical Sciences, University of North Texas Health Science Center, Fort Worth, TX, USA

Full list of author information is available at the end of the article
}

the ON. They originate from retinal ganglion cells (RGCs) in the inner retina and are responsible in transmitting image-forming visual and other signals from the retina to the visual centers and circadian pacemakers in the brain [1]. Damage to these axons leads to RGC apoptotic death, and consequently, loss of vision and disturbance of the circadian rhythm [2].

Apoptosis of RGC involves caspases. Caspases are a family of cysteine proteases that activate apoptotic pathways. They serve as either 'initiators' or 'effectors' based on their molecular functions. The initiator caspases, such as caspases- $2,-8,-9$, and -10 , cleave and activate effector caspases, such as, caspases-3, -6 , and -7 , which, in turn, hydrolyze target proteins and initiate apoptosis [3]. The involvement of specific caspases in optic neuropathy, 
glaucoma, and RGC death has been previously implicated. For example, in the ON of glaucoma patients, more axons were found to express caspase-3 [4]. Similarly, activation of specific caspases occurs in retinas of animal models of ON injury, glaucoma, and RGC degeneration: (a) ON crush activates caspase-2 [5]; (b) ON axotomy activates caspases-3, -6, -8, and -9 in RGCs [6-11]; (c) higher levels of active caspases- $3,-8$, and -9 were shown in the rat retina subjected to chronic ocular hypertension [12-17]; (d) retinal ischemia/reperfusion activates both caspases-2 and $-3[18,19]$ with a reported reduction in caspase-7 expression [19]; and (e) intravitreal injection of kainate cleaved caspase-3 with an increase in effector caspase activity [20]. Interestingly, other than caspase-2 $[5,21]$, inhibition or down-regulation of other initiator caspases or caspase- 3 only provides partial protection against injury-induced RGC death [7-9, 12, 16].

Despite the studies described above, very little is known about the involvement of a unique caspase, caspase-7, in RGC apoptosis. Until recently, contribution of caspase-7 to neuronal apoptosis was controversial. Previously, it was generally believed that caspase- 7 was not present in the CNS, not activated if present, or even if activated, ineffective in inducing apoptosis [22]. Furthermore, because caspase-7 exhibits a high degree of homology with caspase-3, it was speculated that caspase-7 simply served as a redundant version of caspase-3, and thus did not play a critical role in the apoptosis cascade [22]. However, it was later determined that caspase-7 cleaves exclusive substrates different from those of caspase-3, such as kinectin and co-chaperone P23 [2325]. Several other non-ocular studies strongly suggest that caspase-7 has a critical, non-redundant role in apoptotic cell death and in normal development [26, 27]. For example, Larner et al. demonstrated that caspase- 7 is upregulated and activated in the rat brain after traumatic brain injury [28]. Unlike other caspases, only caspase-7 can be activated by calpain-1 [29], indicating that caspase-7 may be a unique concomitant sensor of $\mathrm{Ca}^{2+}$ dysregulation, via changes in calpain-1 activity, and the classical caspase activation, two important death cascades in RGCs.

Thus, the objective of this study is to evaluate the involvement of caspase-7 in ON injury-induced RGC apoptosis in mice. In this study, injury to the ON was produced by intraorbital ON crush, which initiates rapid onset and progression of RGC apoptotic death [30, 31]. We showed that caspase-7, together with its upstream activator calpain-1, were activated and that the selective caspase-7 downstream substrates, P23 and kinectin, were hydrolyzed. We further showed that knockout of caspase-7 significantly both morphologically and functionally protected from the ON crush-induced loss of RGCs.

\section{Results}

\section{Caspase-7 activation by ON injury}

In control, uninjured mouse retinas, the level of activated (cleaved) caspase-7 was typically below the detection limit. Injury to the $\mathrm{ON}$ activated retinal caspase- 7 in a timedependent manner. Activated caspase-7 was not detected in western blots of retinal protein extracts of wild type (WT) mice at pre-injury, as well as $3 \mathrm{~h}$ and $6 \mathrm{~h}$ after ON crush. Active caspase-7 significantly $(p<0.01)$ increased at $12 \mathrm{~h}$ in $\mathrm{ON}$ crushed eyes compared to the uninjured control eyes. Levels continued to increase at $1 \mathrm{~d}$ and $3 \mathrm{~d}(p<0.001)$, and appeared to plateau between $3 \mathrm{~d}$ and $7 \mathrm{~d}$ (Fig. 1), indicating that ON crush activated caspase- 7 in the retina. It is interesting to note that while it takes $3 \mathrm{~d}$ [6] or later [32] for caspase-3 to be activated by ON injury, significant activation of caspase- 7 in our study was observed at as early as $12 \mathrm{~h}$ after injury.

The cellular localization of the activated caspase- 7 in the retina was further evaluated by immunohistochemistry. Consistent with the Western blot analysis, there was no immunoreactivity of cleaved caspase- 7 in the retina

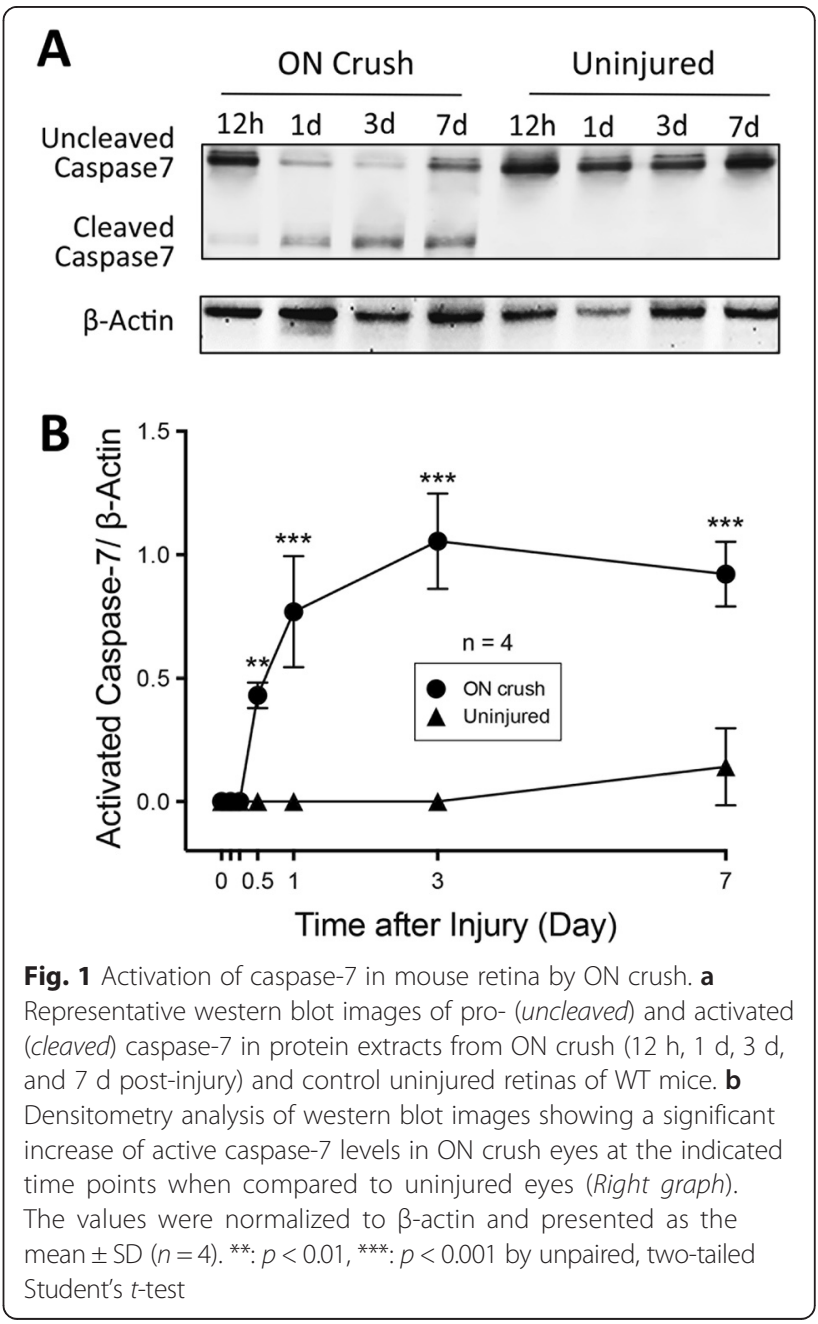


of uninjured eyes (Fig. 2). At $3 \mathrm{~d}$ after $\mathrm{ON}$ crush, there was an obvious increase in the level of cleaved caspase7, which located mainly in the cytoplasm of cells in the ganglion cell layer (GCL) and co-localized with the specific RGC marker, RNA binding protein with multiple splicing (RBPMS) (Fig. 2), indicating that ON crush activates caspase-7 primarily in RGCs.

\section{Association of caspase-7 activation with calpain-1 activation} Calpain activation is associated with neuronal degeneration and cell death in a number of tissues, including the retina. In retinal abnormalities, the calpain pathway is involved in ischemia [33], excitotoxicity [34], experimental glaucoma [35], and photoreceptor degeneration $[36,37]$. Caspase-7, unlike other caspases, is uniquely activated by calpain-1 [29]. Thus, we evaluated whether calpain-1 was involved in ON crush-induced RGC death. Western blot analysis demonstrated that calpain-1 was significantly activated in the retina at early time points of $12 \mathrm{~h}(p<0.05)$ and $1 \mathrm{~d}(p<0.01)$ after ON crush (Fig. 3). However, the level of activated calpain- 1 returned to the basal level prior to $3 \mathrm{~d}$. These findings are consistent with the notion that axonal damage induced a transient activation of calpain-1 that may trigger caspase-7 activation, which in turn contributes to the pro-apoptotic cascade in RGCs.

\section{Cleavage of caspase-7-selective substrates by ON injury} Effector caspases-3 and -7 facilitate apoptosis by hydrolyzing and activating downstream substrates. Some substrates, such as poly (ADP-ribose) polymerase (PARP), are common to both caspases. Other substrates, such as kinectin and co-chaperone P23, are cleaved selectively and more efficiently by caspase- 7 compared to caspase- 3 $[23,25,24]$. Therefore, we tested whether these caspase7 -selective substrates were cleaved in $\mathrm{ON}$ crush-induced retinal injury. To evaluate this, we compared protein extracts of whole retinas from $\mathrm{ON}$ crushed $(7 \mathrm{~d}$ post injury) and uninjured eyes of WT and $\mathrm{Casp}^{--}$mice. We found minimal or undetectable hydrolysis of PARP, kinectin, or P23 in the uninjured retinas of either WT or $\mathrm{Casp}^{-1}$ mice (Fig. 4). Crush of the ON significantly $(p<0.05)$ increased hydrolysis of the non-selective substrate PARP in both mouse strains, while hydrolysis of caspase-7-selective substrates, kinectin and P23, was only observed in the WT but not the Casp $7^{/-}$animals (Fig. 4).

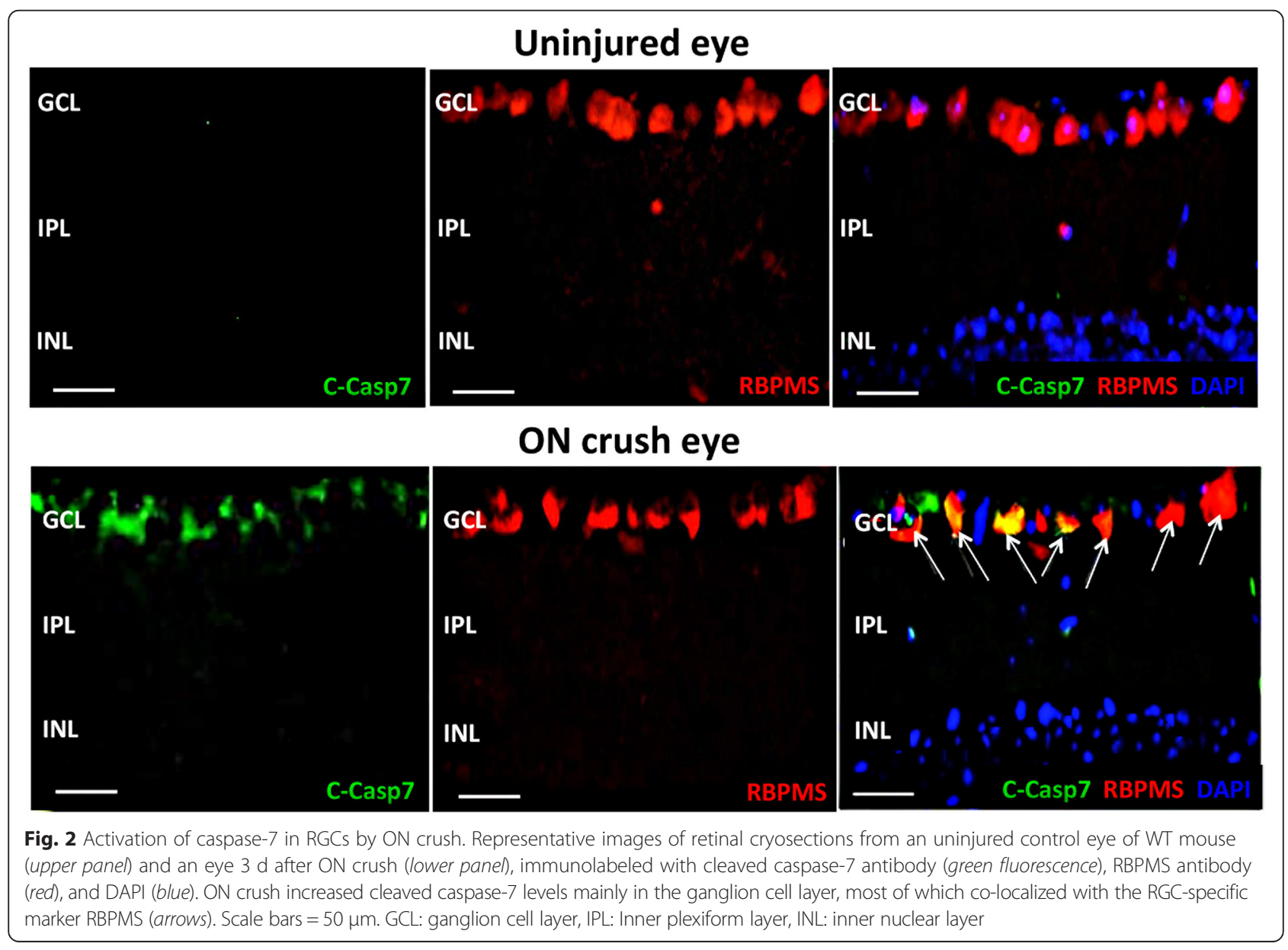




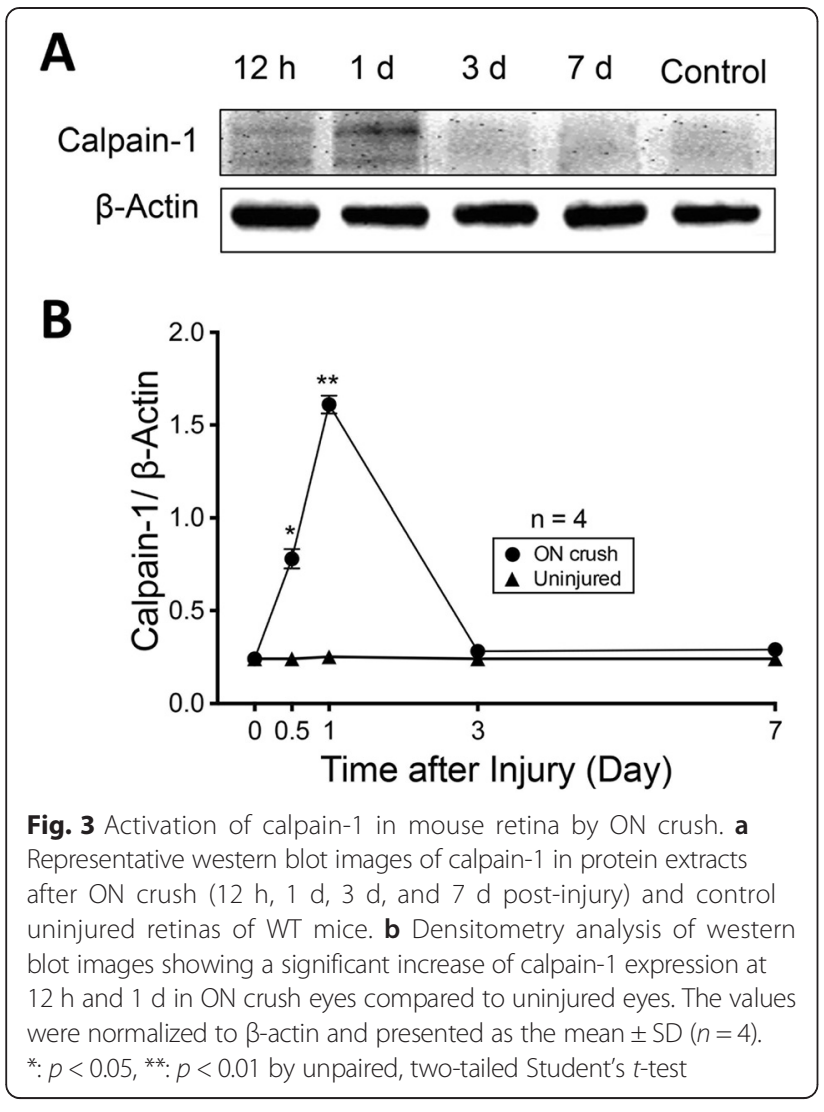

Collectively, these results indicate that $\mathrm{ON}$ crush activates caspase-7.

\section{Protection of Casp7 knockout against ON crush-induced RGC loss}

To assess if caspase-7 activation plays a critical role in ON injury-induced RGC apoptosis, we evaluated the effects of ON crush in $\mathrm{Casp}^{-1-}$ mice compared to WT animals. The $\mathrm{Casp}^{\prime-}$ mouse has been characterized previously [38], and the knockout of caspase-7 protein expression was confirmed in this study (Additional file 1: Figure S1). As shown in retinal cross-sections (Fig. 5a), the densities of RBPMS-positive cells in the GCL of WT and $\mathrm{Casp}^{/-}$mice were similar prior to ON crush. In the WT retinas, the RGC number declined both at $7 \mathrm{~d}$ and $28 \mathrm{~d}$ after $\mathrm{ON}$ crush, while there appeared less loss in the $\operatorname{Casp}^{-1-}$ retina. To quantify this observation, RGCs were counted in RBPMS-labeled retinal flat mounts from each study group. Two 40x images were taken from peripheral and mid-peripheral regions of each of the four quadrants of each retina. Representative flat mount images from mid-peripheral regions are shown in Fig. 5b. The RGC numbers of the eight images from each retina were counted and averaged. Figure $5 \mathrm{c}$ demonstrates that RGC densities in uninjured eyes of WT and Casp $7^{-1}$ animals were similar and stable over the study period. ON crush caused a time-dependent loss of RGCs in WT mice. The loss was statistically significant $(p<0.05)$ at $7 \mathrm{~d}$ after injury, and continued to deteriorate at $14 \mathrm{~d}$ and $28 \mathrm{~d}$. At $28 \mathrm{~d}$, the remaining number of RGCs in the ON crush eyes was $38 \pm 4 \%$ ( $n=6$ retinas) that of the uninjured eyes. In contrast, although the number of RGCs in ON crush eyes of $\mathrm{Casp}^{--}$mice also significantly $(p<0.05)$ decreased starting from $7 \mathrm{~d}$, the extent of RGC loss was significantly $(p<0.05)$ less in the Casp $7^{-1-}$ mice compared to WT mice. Interestingly, the number of RGCs of these animals appeared to stabilize from $7 \mathrm{~d}$ to $28 \mathrm{~d}$ after $\mathrm{ON}$ injury and was statistically different from WT retinas at these time points. At $28 \mathrm{~d}, 76 \pm 3 \%$ of the RGCs remained, which was significantly $(p<0.05)$ higher than that of WT eyes. This finding indicates that knockout of caspase-7 partially protects the RGC loss induced by ON crush, and suggests that caspase-7 plays an important role in this pathophysiological change.

\section{Protection of Casp7 knockout against ON crush-induced thinning of the retina}

In addition to the evaluation of post-mortem retinal tissues, we also used the spectral domain-optical coherence tomography (SD-OCT) to assess in vivo retinal layer thickness of WT and $\mathrm{Casp}^{/-}$mice with or without ON crush. Our previous study showed that ON crush causes thinning of the retina, primarily due to thinning of the ganglion cell complex (GCC; comprising the nerve fiber layer (NFL), GCL, and inner plexiform layer (IPL)) [31]. In the current study, the GCC thicknesses at peripheral and central regions of the retina in uninjured eyes of WT and $\mathrm{Casp}^{-1-}$ animals were equivalent and did not change over the $28 \mathrm{~d}$ study period (Fig. 6). Similar to our previous findings, thinning of GCC occurred at $7 \mathrm{~d}$ $(p<0.05)$ after injury in the ON crush eyes of WT mice. At $28 \mathrm{~d}$, the thickness of GCC was only $68 \pm 6 \%$ and $70 \pm 4 \%$ of the uninjured eyes in peripheral and central retina, respectively. Most importantly, the $\mathrm{ON}$ crush-induced thinning of GCC was partially but significantly $(p<0.05)$ ameliorated in the Casp $^{/-}$mice (Fig. 6). At $28 \mathrm{~d}$ after injury, GCC thickness was $84 \pm 4 \%$ and $87 \pm 5 \%$ of that of uninjured eyes in peripheral and central retina respectively. These results provide temporal in vivo morphological evidence corroborating the protective effects of Casp7 knockout against ON crush-induced RGC loss.

\section{Protection of Casp7 knockout against ON crush-induced loss of RGC function}

In addition to morphological assessments, we also evaluated the potential protection of caspase-7 knockout against ON crush-induced loss of RGC function. The positive STR (pSTR) amplitude in the ERG has been shown to be a useful measurement of RGC function 


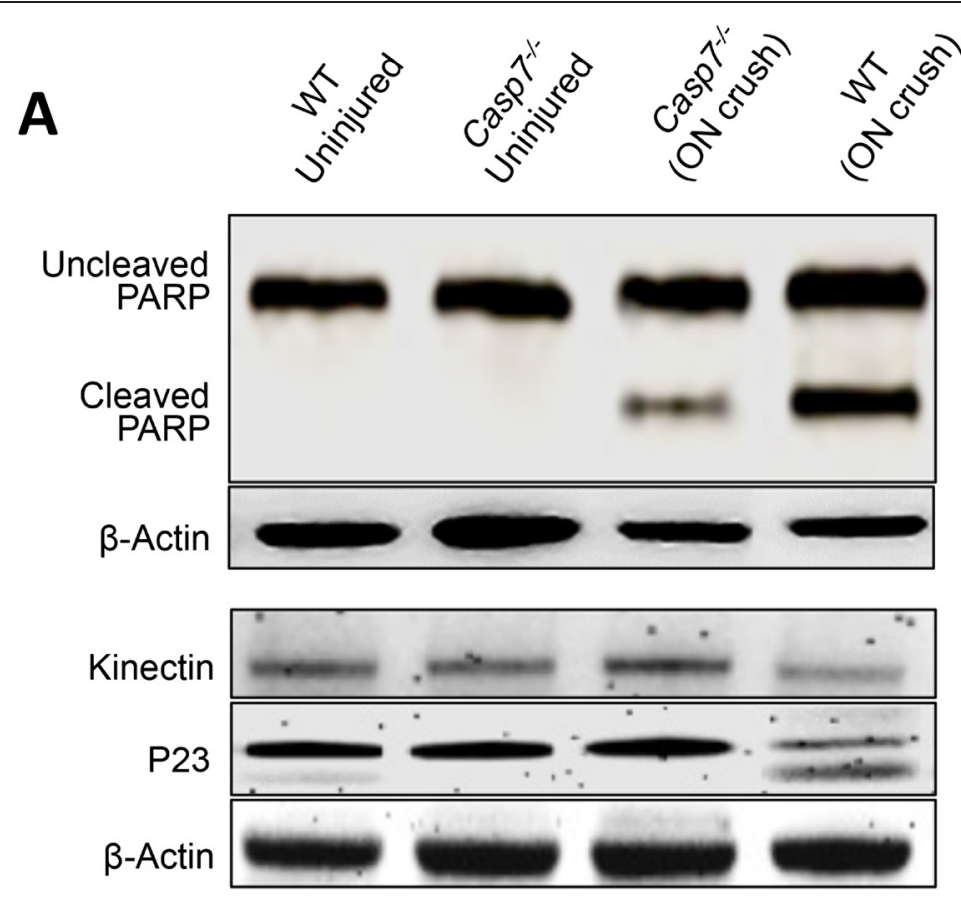

B

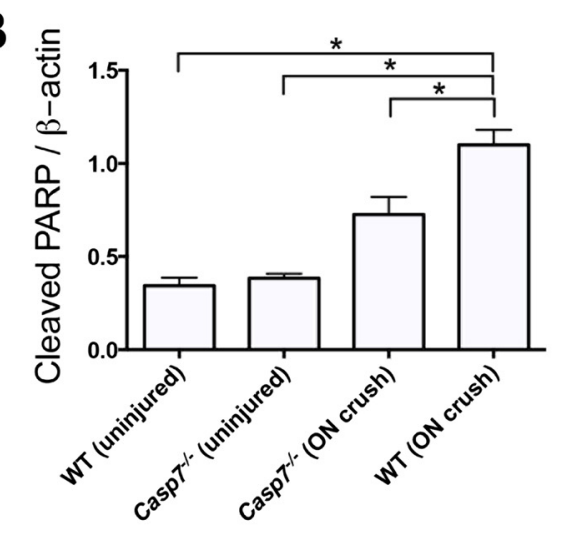

D
C

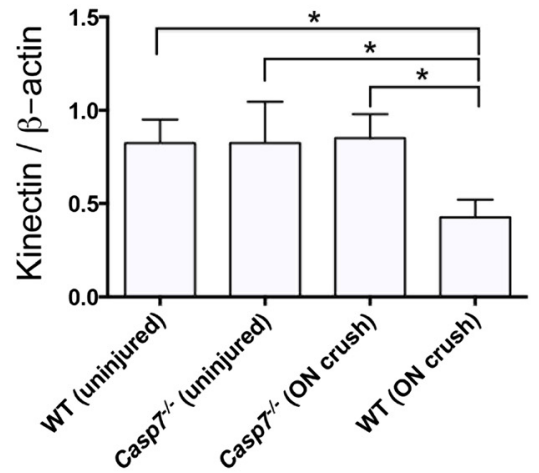

Lower band

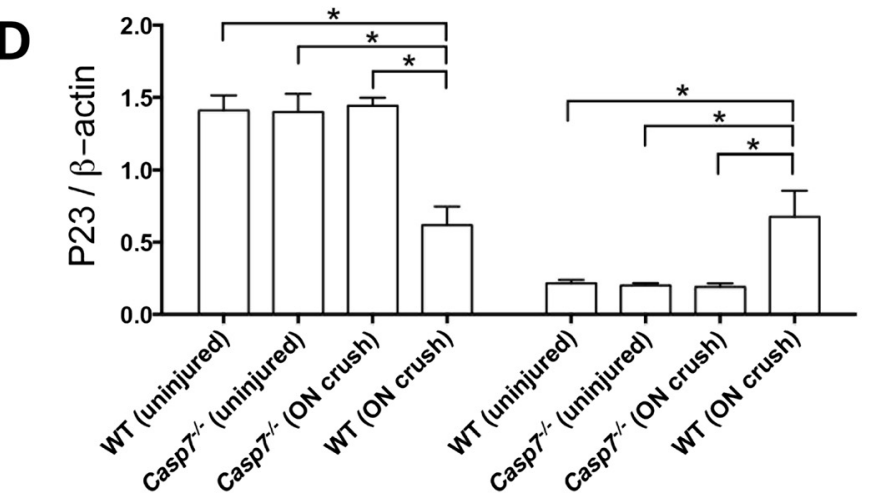

Fig. 4 Cleavage of caspase-7 selective substrates by ON crush. a Representative western blot images of uncleaved and cleaved PARP, kinectin, as well as cleaved and uncleaved co-chaperone P23 in retinal protein extracts from WT or Casp ${ }^{\text {/- }}$ mice, uninjured or $7 \mathrm{~d}$ after ON crush. b-d Densitometry analysis of the corresponding western blot images showing that ON crush induced hydrolysis of kinectin and P23 only in the WT mouse. The values were normalized to $\beta$-actin and presented as the mean \pm SD $(n=4)$. * $p<0.05$ by One Way-ANOVA then Tukey-Kramer post hoc test 

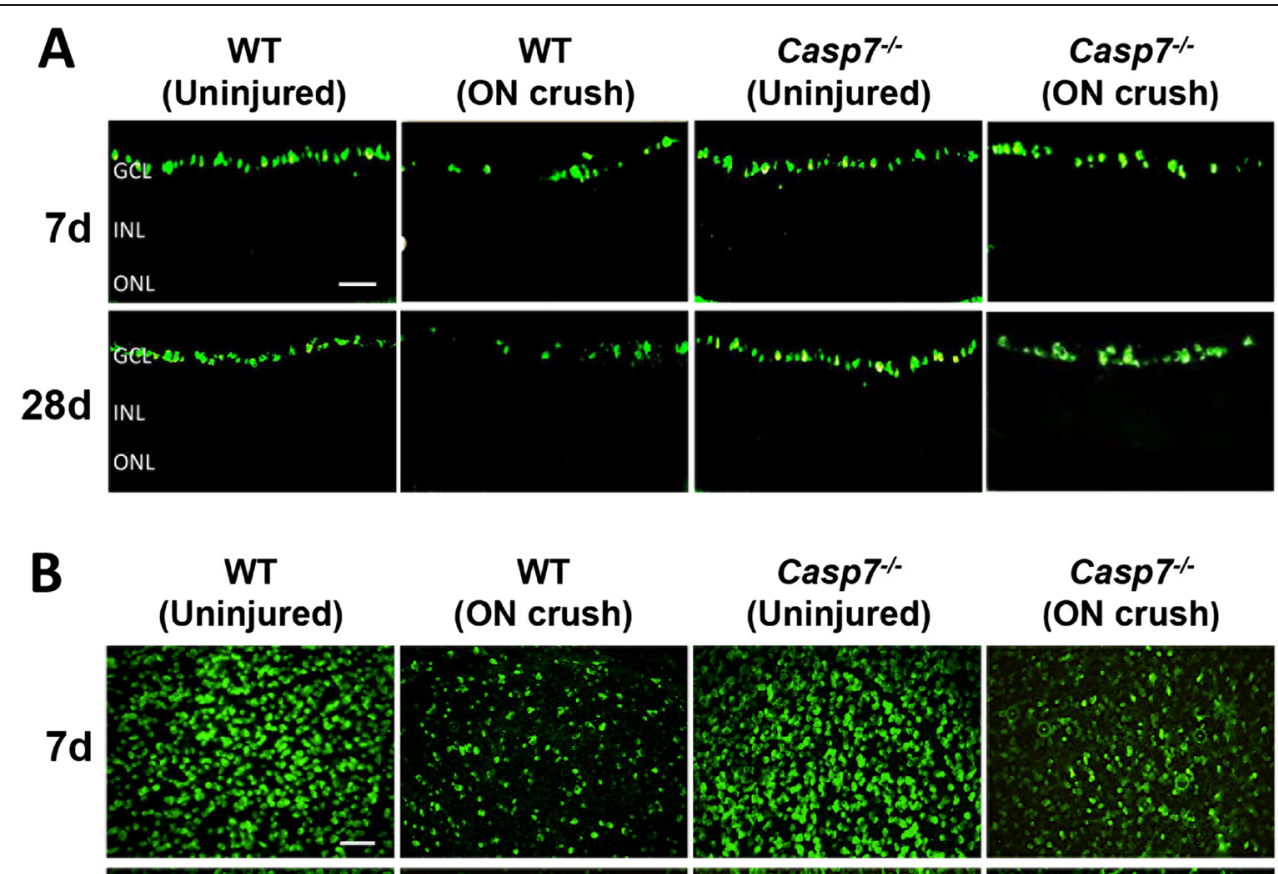

Casp 7--

(ON crush)

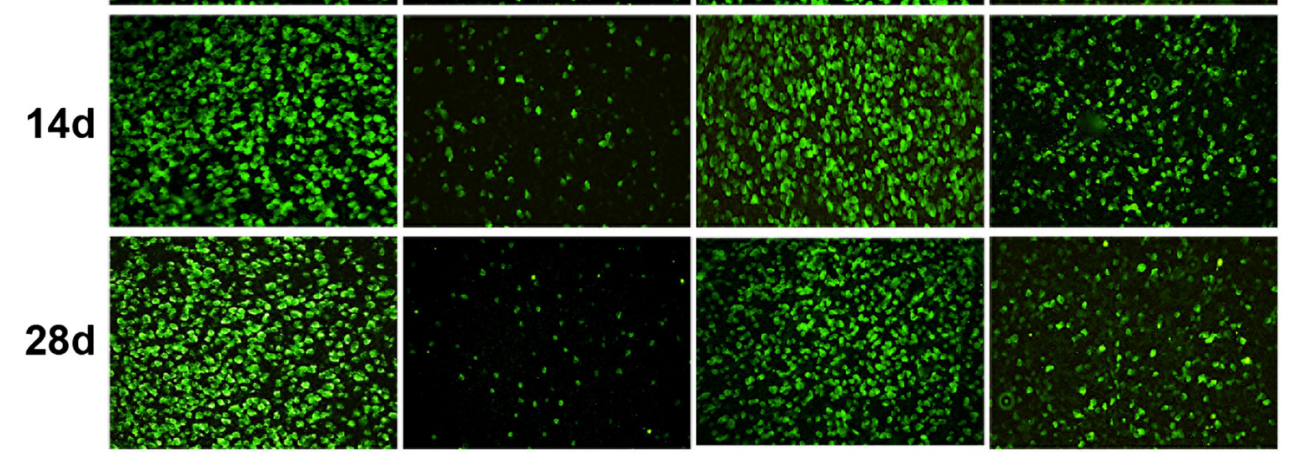

C

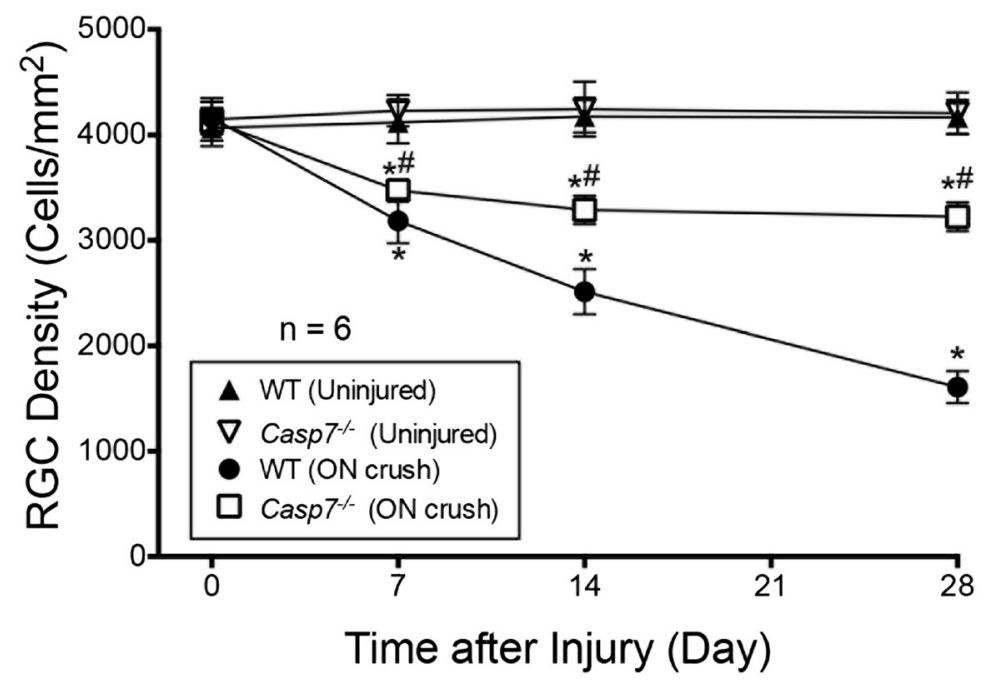

Fig. 5 (See legend on next page.) 
(See figure on previous page.)

Fig. 5 Protection by caspase-7 knockout against ON crush-induced RGC loss. a Representative retina cross-section images with RBPMS immunolabeling of WT and Casp $7^{-1-}$ mice. Images of both ON crush (7 d and $28 \mathrm{~d}$ post injury) and uninjured control eyes are shown. GCL: ganglion cell layer, INL: inner nuclear layer, ONL: outer nuclear layer. Scale bar $=100 \mu \mathrm{m}$. b Representative images showing RBPMS immunolabeled retinal flat-mounts of WT and Casp $^{-1-}$ mice. Images of both ON crush (7 d, $14 \mathrm{~d}$, and $28 \mathrm{~d}$ post injury) and uninjured control eyes are shown. Scale bar $=100 \mu \mathrm{m}$. c Quantitation of RBPMS-positive RGCs in uninjured and ON crush flat-mounted retinas of WT and Casp $7^{-1-}$ mice. There was no difference in RGC densities between uninjured eyes of WT and Casp $7^{\prime-}$ mice. ON crush caused a steady decline in the number of RGCs in WT retina in comparison to Casp $7^{/-}$retina, which showed a significant preservation of RGCs. The values were represented as mean $\pm \mathrm{SD}(n=6) .{ }^{*}: p<0.05$ versus the respective uninjured control group, \#: $p<0.05$ versus the "WT (ON crush)" group by One Way-ANOVA then Tukey-Kramer post hoc test

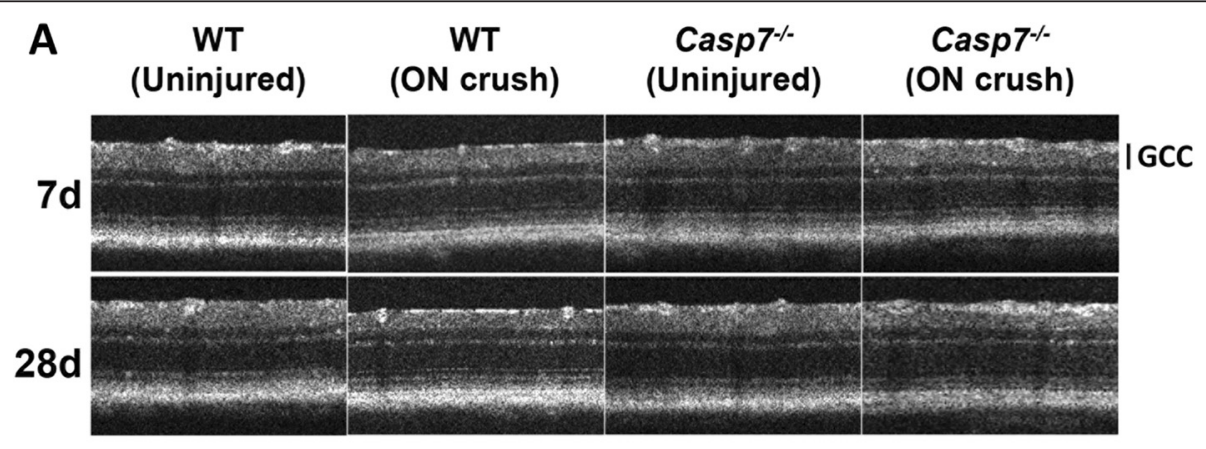

B

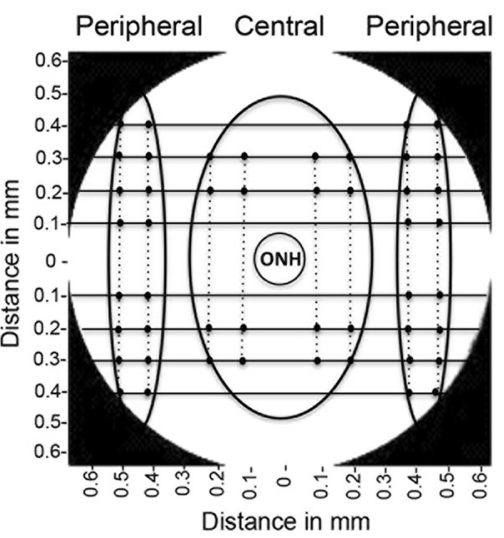

D

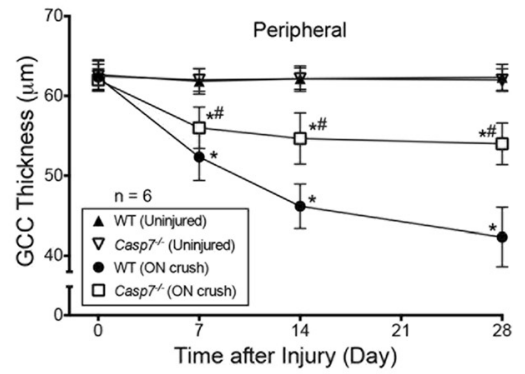

C Distance in $\mathrm{mm}$

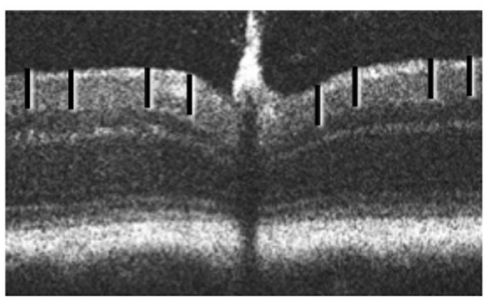

$\mathbf{E}$

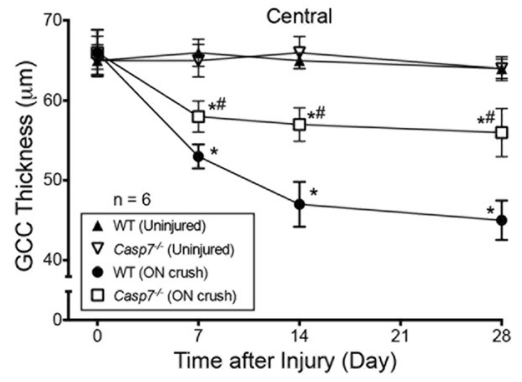

Fig. 6 Protection by caspase-7 knockout against ON crush-induced thinning of retinal layers. a Representative SD-OCT images showing in vivo thickness of retinas of WT and Casp $7^{-1}$ mice. Images of both ON crush (7 d and $28 \mathrm{~d}$ post injury) and uninjured control eyes are shown. GCC = combined thickness of NFL, GCL, and IPL. $\mathbf{b}$ Graphic representation of fundus of mouse eye showing approximate locations of retina thickness measurements. c Cross sectional images of mouse retina. Eight horizontal volume scans of retina at 100, 200,300 and $400 \mu \mathrm{m}$ through the area dorso-temporal from the ON (superior retina, 4 scans) and the area ventro-temporal from the ON (inferior retina, 4 scans) were used to evaluate GCC layer thickness. For measuring the GCC thickness at the peripheral retina, two calibrated calipers were placed at $400 \mu \mathrm{m}$ and $500 \mu \mathrm{m}$ on both sides of the center of each scan/optical slice. The peripheral thickness of the GCC was determined by averaging the 32 measurements. Similarly, to measure the GCC thickness of the central region of the retina, two calibrated calipers were placed at $100 \mu \mathrm{m}$ and $200 \mu \mathrm{m}$ at both sides of the center of each optical slice at 200 and $300 \mu \mathrm{m}$ superior or inferior of the ON head. The central thickness of the GCC was determined by averaging the 16 measurements. Quantitation of GCC thickness in both the peripheral (d) and central (e) retinas of WT and Casp $^{-1-}$ uninjured and ON injured eyes. The values were represented as mean $\pm \mathrm{SD}(n=6){ }^{*}: p<0.05$ versus the respective uninjured control group, \#: $p<0.05$ versus the "WT (ON crush)" group by One-Way ANOVA then Tukey-Kramer post hoc test 
[31]. The pSTR amplitudes of uninjured eyes were similar between WT and Casp $7^{-1}$ mice (Fig. 7). ON crush induced a time-dependent, progressive, and significant $(p<0.05)$ decline in the RGC function in WT mice starting $7 \mathrm{~d}$ after injury. At $28 \mathrm{~d}$, the pSTR was only $39 \pm 8 \%$ of that of uninjured eyes. RGC function was significantly $(p<0.05)$ protected by approximately half in the $\mathrm{Casp}^{-1-}$ mice (Fig. 7). These results demonstrated that knockout of Casp7 partially protected against the ON crush-induced RGC morphological and functional loss.

\section{Discussion}

In many neurodegenerative diseases including glaucoma, axonal injury is a critical insult leading to apoptotic death of RGCs [39-41]. Although previous research has highlighted a central role of caspases as mediators of RGC apoptosis, the specific role of the distinct effector caspase, caspase-7, was not clear. We used ON crush as an experimental model of CNS injury to delineate this relationship. Similar to previous findings [31, 42, 43], we observed a $\sim 60 \%$ decrease in RGC density at $28 \mathrm{~d}$ post injury in adult mice.

We found that caspase-7 was activated in RGCs following $\mathrm{ON}$ crush starting at $12 \mathrm{~h}$ post injury, and activation reached a plateau at $3 \mathrm{~d}$. Consistent with this finding, we also showed the activation of calpain-1, an upstream activator of caspase-7, in the ON crush-injured retina. Since the enzymatic site of caspase- 7 differs from that of caspase- 3 , substrates hydrolyzed by caspase- 7 differ from those of caspase-3. In our study, we observed the hydrolysis of the caspase-7-selective substrates kinectin and cochaperone P23. Together, our results demonstrate that ON crush activates caspase- 7 in the mouse retina.

The finding that caspase- 7 was activated in a majority of RGCs as early as $12 \mathrm{~h}$ after injury is intriguing. In comparison, activation of caspase- 3 begins at $3 \mathrm{~d}$ [6] or later [32] after ON injury and is typically only observed in only a fraction of RGCs, likely those actively going through apoptosis. Since RGC death starts at or after 3 d post ON crush and not all RGCs immediately become apoptotic [31], our findings suggest that caspase-7 activation is involved in an earlier step in the apoptotic signaling cascade. Compared to other caspases, caspase- 7 is unusual in that it can be activated by both the traditional initiator caspase pathway as well as a novel calpain-1 pathway. It is interesting to note that activation of calpain in our study was observed only at 12 and $24 \mathrm{~h}$ after ON crush injury, whereas, activation of caspase-7 was seen up to 7 days post injury. Together these data suggest that caspase- 7 activation may be initiated by the calciumcalpain pathway and sustained by the traditional caspase activation cascade. The functional implication of this unique temporal profile and the exact role that caspase- 7 plays require further investigation.
Although the exact role that caspase-7 activation in ON damage plays remains unclear, biological functions of substrates selectively hydrolyzed by caspase- 7 may provide some clues. Co-chaperone P23, which was hydrolyzed in the injured retina of only WT but not Casp $7^{-1}$ mice, is a ubiquitous protein found in most eukaryote tissues. It binds and stabilizes Heat-shock protein 90 kDa (Hsp90), serves as an essential component of the Hsp90 molecular chaperone complex [44], and interacts with a variety of Hsp90 clients, including most steroid receptors, active telomerase, tyrosine kinases, and transcription factors [45]. In addition, genomic and proteomic studies further revealed an extensive P23 molecular network independent of Hsp90 clients [46]. Most intriguingly, this protein is recognized as a pro-survival factor in cancer cells [25] and perinatal mice [47]. Thus, caspase-7 mediated hydrolysis of P23 will disrupt these intricate biological interactions and may synergize with the canonical caspase-mediated cell death pathway. Kinectin, another caspase-7 selective substrate, is found on the cytoplasmic face of endoplasmic reticulum (ER) membranes [48], as well as the cargo-binding site of conventional kinesins. It has been implicated in the formation, stabilization, shaping, and cytoskeletal interactions of sheet-like cisterns of the ER [49]. As a motor-binding protein, kinectin is also associated with active intracellular organelle movements powered by kinesin, thus controlling intracellular cargo transport [50]. These vital functions of kinectin are expected to be compromised by caspase-7 activation.

To investigate the importance of caspase- 7 in ON crush-induced RGC loss, we assessed the potential RGC protective effects of Casp 7 knockout. Our results showed significant protection of RGCs in the ON crushed eyes of Casp $7^{1-}$ mice when compared to WT mice 7 to $28 \mathrm{~d}$ post crush. We demonstrated this protection using both morphological and functional evaluations. Morphologically, we analyzed post mortem RGC density and measured in vivo thickness of retinal layers. RGC counts of flatmounted retinas indicated that ON crush dramatically reduced the density of these neurons in WT mice, with only $38 \%$ remaining at $28 \mathrm{~d}$ post injury. In contrast, $76 \%$ of the RGCs survived this insult in $\mathrm{Casp}^{1-}$ mice. An interesting observation is that RGC density of these animals appeared to stabilize from $7 \mathrm{~d}$ to $28 \mathrm{~d}$ compared to the continuous decline in the WT animals. This suggests that the protective effect of Casp 7 knockout is not a transient delay of neuronal death, and instead it may provide a long-term protection.

SD-OCT analysis allows non-invasive, in vivo monitoring of morphological changes of the retina. We showed that GCC thickness significantly decreased in WT mice from 7 to $28 \mathrm{~d}$ post $\mathrm{ON}$ crush. GCC is comprised of three retinal layers: the NFL, containing RGC axons; the GCL, containing RGC soma; and the IPL, containing the RGC 


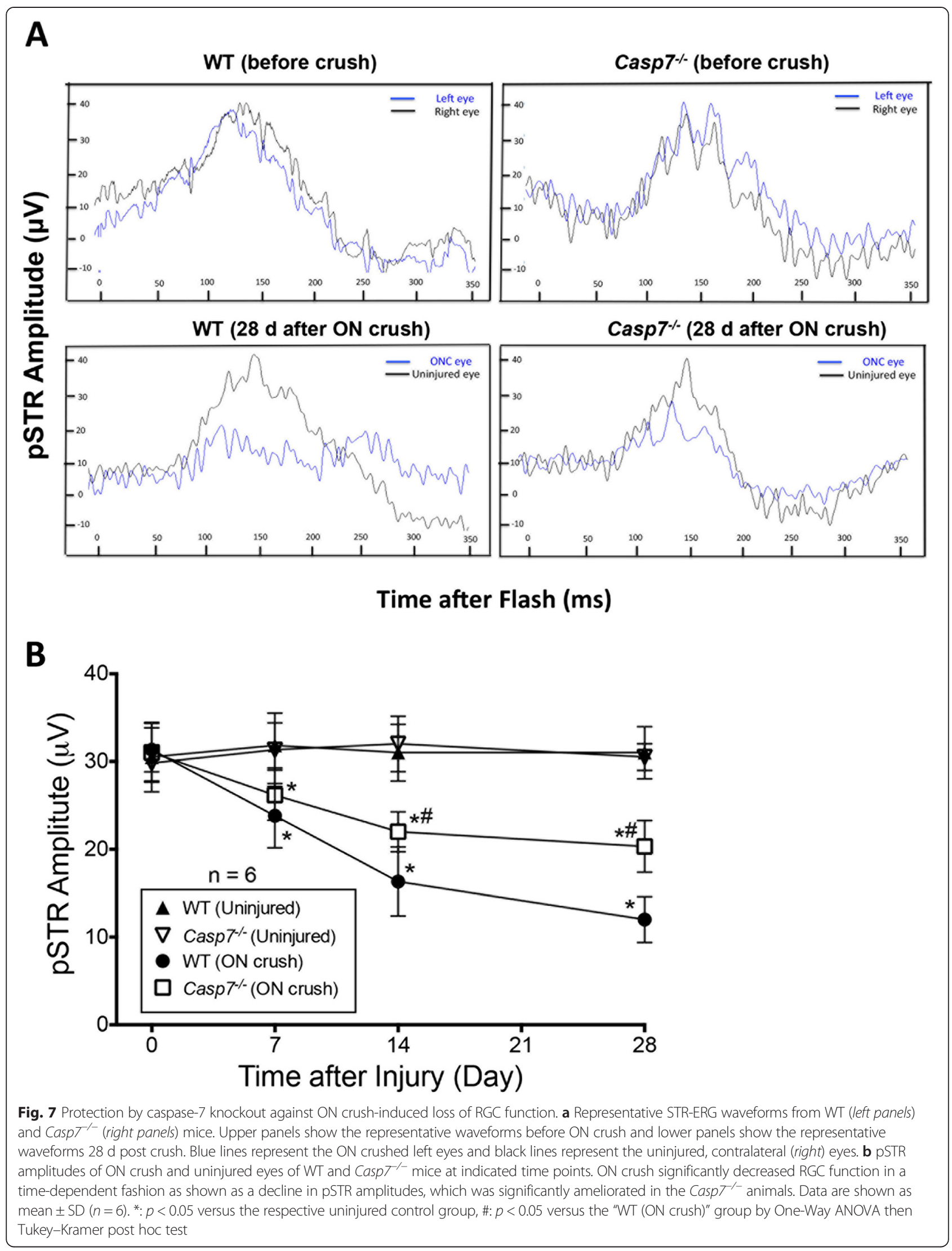


dendrites. ON injury causes loss of RGCs and thinning of the GCC [51-53]. In comparison, ON crush-induced thinning of the GCC was significantly and stably ameliorated in $\mathrm{Casp}^{-1}$ mice from 7 to $28 \mathrm{~d}$ after injury. Together, the in vivo and post mortem results indicate that absence of caspase-7 protects against morphological deterioration of RGCs caused by ON injury.

Most importantly, knockout of Casp7 not only preserved RGC density and structures, but also significantly protected against loss of RGC function subsequent to ON crush. The STR response is derived mainly from RGCs [54]. In WT mice, we found an approximately $35 \%$ decrease in pSTR responses at $7 \mathrm{~d}$ and approximately $65 \%$ at $28 \mathrm{~d}$ after ON crush. This coincides with a time-dependent RGC loss in WT mice after ON crush. In contrast, the pSTR response in $\mathrm{Casp}^{/-}$mice showed only a $15 \%$ reduction at $7 \mathrm{~d}$ and a $25 \%$ decrease at $28 \mathrm{~d}$ after ON crush, clearly showing protection of RGC function.

Our discovery that caspase-7 plays a critical role in ON crush-induced RGC loss is important for the following reasons. Being a concomitant sensor of both the calpain and traditional caspase pathways, caspase-7, through hydrolysis of its specific downstream substrates may regulate unique and yet-to-be-revealed mechanisms in controlling cell death. In addition, caspase-7 is a p53 responsive gene; p53 binds to the first intron of the human and mouse caspase-7 gene [55]. p53 is a transcription factor, involved in the regulation of neuronal viability after injury $[56,57]$. Activated p53 can modulate mitochondrial membrane permeability and the release of mitochondrial proteins during apoptosis. p53 is phosphorylated and its proapoptotic targets PUMA and Fas/CD95 are upregulated in $\mathrm{ON}$ axotomy-induced RGC death [58]. It is interesting to speculate that caspase-7 may be involved in this apoptosis signaling mechanism.

Based on morphological and functional criteria, we showed that Casp7 knockout was protective against ON crush-induced loss of RGCs. However, this protection was not complete (i.e., it did not reach the uninjured levels), suggesting that caspase-7 is not the sole mediator of this ON crush pathology and that other cellular pathways may be involved. It is likely that caspase- 3 also contributes to this injury. This is consistent with the findings that inhibition of caspase-2, an upstream initiator caspase for both caspases- 3 and -7 , via pharmacological inhibition or siRNA provided almost complete protection of RGC against ON crush-induced death for at least 30 days $[5,21]$. Furthermore, caspase-independent pathways may also be involved in neuronal cell death associated with $\mathrm{ON}$ injury, such as mitochondria-mediated death. Mitochondria are essential in controlling cell death. Exposure of RGCs to TNF- $\alpha$ or hypoxia leads to mitochondrial alterations, including the release of cytochrome $\mathrm{c}$ and apoptosis inducing factor, leading to RGC death through caspase-independent events [59]. After ON injury, amplification of TNF- $\alpha$ activates JNK, which causes RGC death [60]. Fernandes et al. have shown that JNK signaling is a major early pathway triggering RGC death after axonal injury [61]. Moreover, reactive oxygen species are associated with mitochondrial dysfunction and may be involved in signaling RGC apoptosis after axonal injury [62]. Therefore, it is clearly important to delineate the relative roles each of these signaling pathways plays and their interactions in ON crush-induced RGC death and other forms of CNS injury.

\section{Conclusions}

In conclusion, our findings demonstrated the important role of caspase-7 in RGC apoptosis induced by $\mathrm{ON}$ crush. Our results also show that knockout of Casp 7 partially protects against ON crush-induced RGC loss and the thinning of inner retinal layer thickness. Most importantly, we found that RGC function was protected by Casp 7 knockout. Thus, inhibition of caspase- 7 activity may be a novel therapeutic strategy for neurodegenerative diseases of the retina and the ON. Further studies need to be performed to unravel the full mechanisms of caspase7 -dependent and independent apoptotic pathways in $\mathrm{ON}$ injury induced RGC apoptosis.

\section{Methods \\ Animals}

Female C57BL/6 J mice, serving as the WT control, and caspase-7 knockout (Casp $\left.7^{-1}\right)$ (B6.129S6-Casp7tm1Flv/J) breeders were purchased from the Jackson Laboratory (Bar Harbor, ME). The Casp $7^{1 /}$ mice were backcrossed with the C57BL/6 J strain for at least 10 generations, making the C57BL/6 J strain an appropriate WT control. All mice were maintained in 12:12 light/dark cycle and supplied with food and water ad libitum. All experiments were conducted in accordance with the ARVO Statement of the Use of Animals in Ophthalmic and Vision Research and the University of North Texas Health Science Center's Institutional Animal Care and Use Committee guidelines.

\section{Optic nerve crush}

ON crush was performed on the left eyes of C57BL/6 J and $\mathrm{Casp}^{-1-}$ mice at 8-10 weeks of age according to a previously described procedure [31]. Briefly, mice were anesthetized by intraperitoneal injection of ketamine and xylazine, (100 and $10 \mathrm{mg} / \mathrm{kg}$ body weight, respectively). The cornea was anesthetized with a topical drop of $0.5 \%$ proparacaine $\mathrm{HCl}$ (Alcon Laboratories, Fort Worth, $\mathrm{TX})$. The $\mathrm{ON}$ of the left eye was exposed intraorbitally through a small opening made among the surrounding extraocular muscles. A pair of self-closing forceps was used to crush the ON approximately $1 \mathrm{~mm}$ behind the 
globe for $4 \mathrm{~s}$. Care was taken not to block the blood flow to the retina through the central retinal artery. The eye was covered with antibiotic ointment (polymyxin B sulfate and bacitracin; Bausch \& Lomb, Tampa, FL). All animals undergoing surgery were given buprenorphine (0.05 mg/kg, subcutaneously) immediately after surgery.

\section{Western blot analysis}

Retinal protein extracts were obtained from dissected retinas by sonication in mammalian protein extraction buffer (Thermo Scientific, Rockford, IL) containing protease inhibitor and phosphatase inhibitor cocktails (Thermo Scientific). Protein concentrations were determined using the Bio-Rad Dc protein assay according to the manufacturer's instructions (Bio-Rad Laboratories, Richmond, CA). A total of $60 \mu \mathrm{g}$ protein from each sample was loaded and electrophoresed on $15 \%$ denaturing polyacrylamide gels and then electrophoretically transferred to polyvinylidene fluoride membranes. Blots were incubated in $5 \%$ milk in Tris Buffered Saline Tween solution (TBST; $20 \mathrm{mM}$ Tris, $0.5 \mathrm{M} \mathrm{NaCl}$, and $0.05 \%$ Tween 20, pH 7.4) for $1 \mathrm{~h}$ to block nonspecific binding. Membranes were incubated overnight at $4{ }^{\circ} \mathrm{C}$ with primary antibodies diluted in Super Block T20 (Thermo Scientific). The primary antibodies used were caspase-7 (1:1000, Cell Signaling, Danvers, MA, Cat \# 9492), calpain-1 (1:1000, Cell Signaling, Cat \# 2556), kinectin (1:1000, Novus Biologicals, Littleton, CO, Cat \# NBP191592), P23 (1:1000, GeneTex, Irvine, CA, Cat \# GTX112655), PARP (1:1000, Cell Signaling, Cat \# 9542), and mouse-anti- $\beta$-actin (1:5000; clone C4, Millipore, Billerica, MA, Cat \# MAB1501). The following day, membranes were washed with TBST $3 \mathrm{X}$ for a total of $30 \mathrm{~min}$ and were incubated for $1 \mathrm{~h}$ with corresponding secondary antibodies: goat-anti-rabbit-horseradish peroxidase (1:10,000; Thermo Scientific, Cat \# 32460) or goat-antimouse-horseradish peroxidase conjugated antibodies (1:10,000; Thermo Scientific, Cat \# 32430) diluted in TBST. Membranes were washed 3X with TBST for 10 min each at room temperature. The proteins were then visualized in a FluorChem 8900 imager (Alpha Innotech, San Leandro, CA) using ECL detection reagent Super Signal West Femto Maximum Sensitivity Substrate (Thermo Scientific). The relative expression of proteins was determined by densitometry analysis and then normalized to $\beta$-actin.

\section{Immunohistochemistry}

Eyes from WT and $\mathrm{Casp}^{-1-}$ mice were enucleated and fixed overnight in freshly prepared $4 \%$ paraformaldehyde (PFA) in phosphate-buffered saline (PBS). Afterwards, eyes were submerged sequentially in solutions of $10 \%, 20 \%$ and $30 \%$ sucrose for at least $1 \mathrm{~h}$ each. Eyes were embedded in cryostat compound (Tissue TEK OCT, Sakura Finetek, Torrance, CA) and frozen at $-80{ }^{\circ} \mathrm{C}$.
Sections $(10 \mu \mathrm{m}$ thick) were cut using a cryostat (Leica Microsystem, Buffalo Grove, IL) and transferred to glass slides. Retinal cryosections were soaked in PBS for $10 \mathrm{~min}$ and blocked in $2 \%$ goat serum, $0.3 \%$ Triton X-100 in PBS for $1 \mathrm{~h}$ at room temperature. The sections were double immunolabeled with mouse monoclonal caspase-7 antibody (1:50, Santacruz Biotechnology, Dallas, TX, Cat \# SC-28295) and rabbit polyclonal RBPMS antibody (1:200, Genetex, Irvine, CA Cat \# GTX118619) overnight at $4{ }^{\circ} \mathrm{C}$, washed three times with PBS and incubated for $1 \mathrm{~h}$ with the respective secondary antibodies at room temperature. Secondary antibodies used were AlexaFluor488 goat-antirabbit (1:1000; Life Technologies, Grand Island, NY, Cat \# A11008) and tetramethylrhodamine goat-anti-mouse IgG (1:1000; Life Technologies, cat \# T2762). Sections were mounted with Vectashield Mounting Medium containing DAPI (Vector Laboratories, Burlingame, CA). Images were acquired using a Carl Zeiss inverted microscope Axiom vision series (Carl Zeiss Microscopy, Thornwood NY).

\section{Retinal flat mounts and cell counts}

Following fixation in $4 \%$ PFA, the anterior segment of each eye was removed and the posterior eyecup was processed for whole mount immunostaining to quantitate RGCs. Retinas from fixed eyes were carefully dissected, flat-mounted on glass slides, and blocked in $0.3 \%$ Triton X-100 in PBS containing $2 \%$ goat serum for $2 \mathrm{~h}$. Retinas were then incubated in rabbit polyclonal RBPMS antibody (1:200, diluted in $0.3 \%$ Triton X-100 in PBS) overnight at $4{ }^{\circ} \mathrm{C}$. Following washes in PBS, the retinas were incubated with AlexaFluor488 goat-antirabbit (1:1000, diluted in PBST) for $24 \mathrm{~h}$ at $4{ }^{\circ} \mathrm{C}$ and then mounted with Vectashield Mounting Medium containing DAPI (Vector Laboratories). Eight 40x images were taken from peripheral and mid-peripheral regions of the four quadrants of each retina. The number of labeled cells from each image was counted. For each individual retina, the RGC count was obtained by averaging the eight counts for each retina.

\section{Spectral domain-optical coherence tomography}

SD-OCT imaging was performed using the Bioptigen Envisu $^{\text {tix }}$ Ophthalmic Imaging System (Bioptigen, Durham, $\mathrm{NC}$ ) to measure GCC thickness (combination of NFL, GCL, and IPL layers). Mice were anesthetized using a ketamine/xylazine cocktail $(100 / 10 \mathrm{mg} / \mathrm{kg})$, and their $\mathrm{pu}$ pils were dilated with a drop of $2.5 \%$ phenylephrine hydrochloride (Bausch \& Lomb). To prevent corneal desiccation during the procedure, topical Systane Ultra ${ }^{\circ}$ lubricant eye drop (Alcon) was applied frequently and bilaterally. The retina was scanned with the rectangular scanning mode consisting of $100 \mathrm{~B}$-scan tomograms, each with $1000 \mathrm{~A}$-scans, by using InVivoVue software (Bioptigen 
Inc. Durham, NC). Horizontal volume scans of retina at $100,200,300$ and $400 \mu \mathrm{m}$ through the area dorso-temporal of the ON head (superior retina) and the area ventrotemporal of the $\mathrm{ON}$ head (inferior retina) were used to evaluate the thickness of the GCC. For measuring the GCC thickness at peripheral retina, two calibrated calipers were placed at $400 \mu \mathrm{m}$ and $500 \mu \mathrm{m}$ on both sides from the center of each of the eight optical slices. The peripheral GCC thickness of each retina was determined by averaging the 32 measurements. To determine GCC thickness at central retina, two calibrated calipers were placed at $100 \mu \mathrm{m}$ and $200 \mu \mathrm{m}$ on both sides of the center of optical slices that were 200 and $300 \mu \mathrm{m}$ superior or inferior to the ON head. The central thickness of the GCC of each retina was determined by averaging the 16 measurements.

\section{Scotopic threshold response electroretinography}

The STR of ERG was performed with the Handheld Multispecies-ElectroRetinoGraph unit (Ocuscience, Kansas City, $\mathrm{MO})$ to assess the functional analysis of RGCs [31]. Mice were dark-adapted overnight prior to ERG recordings. During the whole procedure, mice were anesthetized using $1.5 \%$ isoflurane. The mouse pupils were dilated with a drop of $2.5 \%$ phenylephrine, and the cornea was anesthetized with a drop of $0.5 \%$ proparacaine. A ground electrode was inserted subcutaneously in the tail and two reference electrodes were inserted subcutaneously underneath both eyes. Recording electrodes were placed on the cornea. To maintain moisture, a drop of $2.5 \%$ methylcellulose was added to the concave side of a contact lens, which was placed on the electrodes. Light stimuli $(0.03$ $\mathrm{mcd} \cdot \mathrm{s} / \mathrm{m}^{2}$ ) were generated in a Ganzfeld dome with light emitting diodes. Responses from 10 flashes with $2 \mathrm{~s}$ intervals were averaged. The positive component of the STR amplitude was quantified and analyzed by using ERGVIEW software (Ocuscience).

\section{Statistical analysis}

Results between two groups were analyzed for differences using the unpaired Student's $t$-test (GraphPad Prism 6.0; GraphPad Software, La Jolla, CA). Results among three or more groups were compared using oneway ANOVA followed by Tukey-Kramer post hoc test. Statistical significance was determined at $\mathrm{p}$ values $<0.05$.

\section{Additional file}

Additional file 1: Figure S1. Reduction in caspase-7 expression in the retina of Casp $7^{-1-}$ mice. Representative western blot images of pro-caspase-7 in protein extracts from retinas from WT and $\mathrm{Casp}^{7^{-1}}$ mice. (TIFF $42 \mathrm{~kb}$ )

\section{Abbreviations}

Casp $7^{-1-}$ : Caspase-7 knockout; CNS: Central nervous system; ER: Endoplasmic reticulum; GCC: Ganglion cell complex; GCL: Ganglion cell layer; Hsp90: Heat-shock protein 90 kDa; INL: Inner nuclear layer; IPL: Inner plexiform layer;
NFL: Nerve fiber layer; ON: Optic nerve; PARP: Poly (ADP-ribose) polymerase; pSTR: Positive component of the scotopic threshold response; RBPMS: RNA-binding protein with multiple splicing; RGC: Retinal ganglion cell; SD-OCT: Spectral domain-optical coherence tomography; WT: Wild type.

\section{Competing interests}

The authors declare that they have no competing interest.

\section{Authors' contributions}

SC performed ON crush, sample harvesting, Western blotting, Immunohistochemistry, fluorescence microscopy, retinal flat mounts, Optical coherence tomography, Scotopic Threshold Response-Electroretinogram and the data analysis. YL also performed some of the ON crush, sample processing, and actively participated in the design and coordination of the study. IHP participated in the design of the study, statistical analysis as well as reviewed the data. AFC reviewed all data, participated in the design and coordination of the study as well as revising the manuscript. Manuscript was written by SC and IHP with revisions from AFC and YL. All authors read and approved the final manuscript.

\section{Acknowledgement}

This work was supported by a grant from the Department of Defense (VISION 10-2-0003 to AFC).

\section{Author details}

${ }^{1}$ North Texas Eye Research Institute, University of North Texas Health Science Center, 3500 Camp Bowie Blvd, Fort Worth, TX 76107, USA. ${ }^{2}$ Pharmaceutical Sciences, University of North Texas Health Science Center, Fort Worth, TX, USA. ${ }^{3}$ Cell Biology \& Immunology, University of North Texas Health Science Center, Fort Worth, TX, USA.

Received: 14 April 2015 Accepted: 19 August 2015

Published online: 26 August 2015

\section{References}

1. Berson DM, Dunn FA, Takao M. Phototransduction by retinal ganglion cells that set the circadian clock. Science. 2002;295(5557):1070-3. doi:10.1126/science.1067262.

2. Drouyer E, Dkhissi-Benyahya O, Chiquet C, WoldeMussie E, Ruiz G, Wheeler LA, et al. Glaucoma alters the circadian timing system. PLoS One. 2008;3(12):e3931. doi:10.1371/journal.pone.0003931.

3. Tait SW, Green DR. Mitochondria and cell death: outer membrane permeabilization and beyond. Nat Rev Mol Cell Biol. 2010;11(9):621-32. doi:10.1038/nrm2952.

4. Zalewska R, Zalewski B, Reszec J, Mariak Z, Zimnoch L, Proniewska-Skretek E. The expressions of Fas and caspase-3 in human glaucomatous optic nerve axons. Med Sci Monit. 2008;14:BR274-8.

5. Ahmed Z, Kalinski H, Berry M, Almasieh M, Ashush H, Slager N, et al. Ocular neuroprotection by siRNA targeting caspase-2. Cell Death Dis. 2011;2:e173. doi:10.1038/cddis.2011.54.

6. Kermer P, Klocker N, Labes M, Thomsen S, Srinivasan A, Bahr M. Activation of caspase-3 in axotomized rat retinal ganglion cells in vivo. FEBS Lett. 1999:453:361-4

7. Kermer P, Ankerhold R, Klocker N, Krajewski S, Reed JC, Bahr M. Caspase-9: involvement in secondary death of axotomized rat retinal ganglion cells in vivo. Mol Brain Res. 2000;85:144-50.

8. Kurimoto T, Miyoshi T, Suzuki A, Yakura T, Watanabe M, Mimura O, et al. Apoptotic death of beta cells after optic nerve transection in adult cats. J Neurosci. 2003;23(10):4023-8.

9. Weishaupt JH, Diem R, Kermer P, Krajewski S, Reed JC, Bahr M. Contribution of caspase-8 to apoptosis of axotomized rat retinal ganglion cells in vivo. Neurobiol Dis. 2003;13:124-35.

10. Cheung ZH, Chan Y-M, Siu FKW, Yip HK, Wu W, Leung MCP, et al. Regulation of caspase activation in axotomized retinal ganglion cells. Mol Cell Neurosci. 2004;25:383-93.

11. Monnier PP, D'Onofrio PM, Magharious M, Hollander AC, Tassew N, Szydlowska K, et al. Involvement of caspase-6 and caspase-8 in neuronal apoptosis and the regenerative failure of injured retinal ganglion cells. J Neurosci. 2011;31(29):10494-505. 
12. Hanninen VA, Pantcheva MB, Freeman EE, Poulin NR, Grosskreutz CL. Activation of caspase 9 in a rat model of experimental glaucoma. Curr Eye Res. 2002;25:389-95.

13. McKinnon SJ, Lehman DM, Kerrigan-Baumrind LA, Merges CA, Pease ME, Kerrigan DF, et al. Caspase activation and amyloid precursor protein cleavage in rat ocular hypertension. Invest Ophthalmol Vis Sci. 2002;43:1077-87.

14. Tahzib NG, Ransom NL, Reitsamer HA, McKinnon SJ. Alpha-fodrin is cleaved by caspase-3 in a chronic ocular hypertension $(\mathrm{COH})$ rat model of glaucoma. Brain Res Bull. 2004;62:491-5.

15. Huang W, Dobberfuhl A, Filippopoulos T, Ingelsson M, Fileta JB, Poulin NR, et al. Transcriptional up-regulation and activation of initiating caspases in experimental glaucoma. Am J Pathol. 2005;167:673-81.

16. Kim HS, Park CK. Retinal ganglion cell death is delayed by activation of retinal intrinsic cell survival program. Brain Res. 2005;1057:17-28.

17. Levkovitch-Verbin H, Harizman N, Dardik R, Nisgav Y, Vander S, Melamed S Regulation of cell death and survival pathways in experimental glaucoma. Exp Eye Res. 2007:85:250-8

18. Lam TT, Abler AS, Tso MOM. Apoptosis and caspases after ischemia-reperfusion injury in rat retina. Invest Ophthalmol Vis Sci. 1999:40:967-75

19. Produit-Zengaffinen N, Pournaras CJ, Schorderet DF. Retinal ischemiainduced apoptosis is associated with alteration in Bax and $\mathrm{BCl}-\mathrm{x}(\mathrm{L})$ expression rather than modifications in Bak and $\mathrm{BCl}-2$. Mol Vis. 2009;15:2101-10

20. Lulli M, Witort E, Papucci L, Torre E, Schipani C, Bergamini C, et al. Coenzyme Q10 instilled as eye drops on the cornea reaches the retina and protects retinal layers from apoptosis in a mouse model of kainate-induced retinal damage. Invest Ophthalmol Vis Sci. 2012;53(13):8295-302. doi:10.1167/iovs.12-10374.

21. Visgneswara V, Berry M, Logan A, Ahmed Z. Pharmacological inhibition of caspase-2 protects axotomised retinal ganglion cells from apoptosis in adult rats. PLoS One. 2012;7(12):e53473.

22. Lamkanfi M, Kanneganti TD. Caspase-7: a protease involved in apoptosis and inflammation. Int J Biochem Cell Biol. 2010;42(1):21-4 doi:10.1016/j.biocel.2009.09.013.

23. Machleidt T, Geller P, Schwandner R, Scherer G, Kronke M. Caspase 7-induced cleavage of kinectin in apoptotic cells. FEBS Lett. 1998;436:51-4.

24. Boucher D, Blais V, Denault JB. Caspase-7 uses an exosite to promote poly(ADP ribose) polymerase 1 proteolysis. Proc Natl Acad Sci U S A. 2012;109(15):5669-74. doi:10.1073/pnas.1200934109.

25. Patwardhan CA, Fauq A, Peterson LB, Miller C, Blagg BS, Chadli A. Gedunin inactivates the co-chaperone p23 protein causing cancer cell death by apoptosis. J Biol Chem. 2013;288(10):7313-25. doi:10.1074/jbc.M112.427328.

26. Walsh JG, Cullen SP, Sheridan C, Luthi AU, Gerner C, Martin SJ. Executioner caspase-3 and caspase-7 are functionally distinct proteases. Proc Natl Acad Sci U S A. 2008;105(35):12815-9. doi:10.1073/pnas.0707715105.

27. Demon D, Van Damme P, Vanden Berghe T, Deceuninck A, Van Durme J, Verspurten J, et al. Proteome-wide substrate analysis indicates substrate exclusion as a mechanism to generate caspase-7 versus caspase-3 specificity. Mol Cell Proteomics. 2009;8(12):2700-14. doi:10.1074/ mcp.M900310-MCP200

28. Larner SF, McKinsey DM, Hayes RL, Wang KKW. Caspase 7: increased expression and activation after traumatic brain injury in rats. J Neurochem. 2005;94(1):97-108. doi:10.1111/j.1471-4159.2005.03172.x.

29. Gafni J, Cong X, Chen SF, Gibson BW, Ellerby LM. Calpain-1 cleaves and activates caspase-7. J Biol Chem. 2009:284(37):25441-9. doi:10.1074/jbc.M109.038174

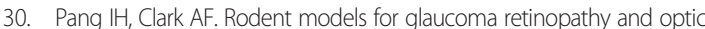
neuropathy. J Glaucoma. 2007;16(5):483-505. doi:10.1097/IJG.0b013e3181405d4f

31. Liu Y, McDowell CM, Zhang Z, Tebow HE, Wordinger RJ, Clark AF. Monitoring retinal morphologic and functional changes in mice following optic nerve crush. Invest Ophthalmol Vis Sci. 2014;55(6):3766-74. doi:10.1167/iovs.14-13895.

32. Levkovitch-Verbin H, Dardik R, Vander S, Melamed S. Mechanism of retinal ganglion cells death in secondary degeneration of the optic nerve. Exp Eye Res. 2010;91(2):127-34. doi:10.1016/j.exer.2009.11.014.

33. Azuma M, Shearer TR. The role of calcium-activated protease calpain in experimental retinal pathology. Surv Ophthalmol. 2008;53(2):150-63. doi:10.1016/j.survophthal.2007.12.006.
34. Nakazawa T, Shimura M, Mourin R, Kondo M, Yokokura S, Saido TC, et al. Calpain-mediated degradation of $\mathrm{G}$-substrate plays a critical role in retinal excitotoxicity for amacrine cells. J Neurosci Res. 2009;87(6):1412-23. doi:10.1002/jnr.21953.

35. Huang W, Fileta J, Rawe I, Qu J, Grosskreutz CL. Calpain activation in experimental glaucoma. Invest Ophthalmol Vis Sci. 2010;51(6):3049-54.

36. Mizukoshi S, Nakazawa M, Sato K, Ozaki T, Metoki T, Ishiguro S. Activation of mitochondrial calpain and release of apoptosis-inducing factor from mitochondria in RCS rat retinal degeneration. Exp Eye Res. 2010;91(3):353-61. doi:10.1016/j.exer.2010.06.004.

37. Paquet-Durand F, Sanges D, McCall J, Silva J, van Veen T, Marigo V, et al. Photoreceptor rescue and toxicity induced by different calpain inhibitors. J Neurochem. 2010;115(4):930-40. doi:10.1111/j.1471-4159.2010.06983.x.

38. Choudhury S, Bhootada Y, Gorbatyuk O, Gorbatyuk M. Caspase-7 ablation modulates UPR, reprograms TRAF2-JNK apoptosis and protects T17M rhodopsin mice from severe retinal degeneration. Cell Death Dis. 2013;4:e528. doi:10.1038/cddis.2013.34

39. Howell GR, Libby RT, Jakobs TC, Smith RS, Phalan FC, Barter JW, et al. Axons of retinal ganglion cells are insulted in the optic nerve early in DBA/2 J glaucoma. J Cell Biol. 2007;179(7):1523-37. doi:10.1083/jcb.200706181.

40. Schlamp CL, Li Y, Dietz JA, Janssen KT, Nickells RW. Progressive ganglion cell loss and optic nerve degeneration in DBA/2 J mice is variable and asymmetric. BMC Neurosci. 2006:7:66. doi:10.1186/1471-2202-7-66.

41. Quigley HA, Hohman RM, Addicks EM, Massof RW, Green WR. Morphologic changes in the lamina cribrosa correlated with neural loss in open-angle glaucoma. Am J Ophthalmol. 1983;95(5):673-91.

42. Allcutt D, Berry M, Sievers J. A quantitative comparison of the reactions of retinal ganglion cells to optic nerve crush in neonatal and adult mice. Brain Res. 1984;318(2):219-30.

43. Li Y, Schlamp CL, Nickells RW. Experimental induction of retinal ganglion cell death in adult mice. Invest Ophthalmol Vis Sci. 1999:40(5):1004-8.

44. Johnson JL, Toft DO. A novel chaperone complex for steroid receptors involving heat shock proteins, immunophilins, and p23. J Biol Chem. 1994;269(40):24989-93.

45. Felts SJ, Toft DO. p23, a simple protein with complex activities. Cell Stress Chaperones. 2003;8(2):108-13.

46. Echtenkamp FJ, Zelin E, Oxelmark E, Woo JI, Andrews BJ, Garabedian M, et al. Global functional map of the p23 molecular chaperone reveals an extensive cellular network. Mol Cell. 2011;43(2):229-41. doi:10.1016/ j.molcel.2011.05.029.

47. Grad I, McKee TA, Ludwig SM, Hoyle GW, Ruiz P, Wurst W, et al. The Hsp90 cochaperone p23 is essential for perinatal survival. Mol Cell Biol. 2006;26(23):8976-83. doi:10.1128/mcb.00734-06.

48. Toyoshima I, Yu H, Steuer ER, Sheetz MP. Kinectin, a major kinesin-binding protein on ER. J Cell Biol. 1992;118(5):1121-31.

49. Goyal U, Blackstone C. Untangling the web: mechanisms underlying ER network formation. Biochim Biophys Acta. 2013;1833(11):2492-8. doi:10.1016/j.bbamcr.2013.04.009.

50. Sheetz MP. Motor and cargo interactions. Eur J Biochem. 1999;262(1):19-25.

51. Arintawati $P$, Sone T, Akita T, Tanaka J, Kiuchi $Y$. The applicability of ganglion cell complex parameters determined from SD-OCT images to detect glaucomatous eyes. J Glaucoma. 2013;22(9):713-8. doi:10.1097/ IJG.0b013e318259b2e1.

52. Gabriele ML, Ishikawa H, Schuman JS, Ling Y, Bilonick RA, Kim JS, et al. Optic nerve crush mice followed longitudinally with spectral domain optical coherence tomography. Invest Ophthalmol Vis Sci. 2011;52(5):2250-4. doi:10.1167/iovs.10-6311.

53. Giani A, Thanos A, Roh MI, Connolly E, Trichonas G, Kim I, et al. In vivo evaluation of laser-induced choroidal neovascularization using spectraldomain optical coherence tomography. Invest Ophthalmol Vis Sci. 2011;52(6):3880-7. doi:10.1167/iovs.10-6266.

54. Alarcon-Martinez L, Aviles-Trigueros M, Galindo-Romero C, Valiente-Soriano J, Agudo-Barriuso M, Villa Pde L, et al. ERG changes in albino and pigmented mice after optic nerve transection. Vis Res. 2010;50(21):2176-87. doi:10.1016/j.visres.2010.08.014.

55. Yang C, Kaushal V, Haun RS, Seth R, Shah SV, Kaushal GP. Transcriptional activation of caspase- 6 and -7 genes by cisplatin-induced p53 and its functional significance in cisplatin nephrotoxicity. Cell Death Differ. 2008;15(3):530-44. doi:10.1038/sj.cdd.4402287. 
56. Wood KA, Youle RJ. The role of free radicals and p53 in neuron apoptosis in vivo. J Neurosci. 1995;15(8):5851-7.

57. Chatoo W, Abdouh M, Bernier G. p53 pro-oxidant activity in the central nervous system: implication in aging and neurodegenerative diseases. Antioxid Redox Signal. 2011;15(6):1729-37. doi:10.1089/ars.2010.3610.

58. Wilson AM, Morquette B, Abdouh M, Unsain N, Barker PA, Feinstein E, et al. ASPP1/2 regulate p53-dependent death of retinal ganglion cells through PUMA and Fas/CD95 activation in vivo. J Neurosci. 2013;33(5):2205-16. doi:10.1523/JNEUROSCI.2635-12.2013.

59. Tezel G, Yang X. Caspase-independent component of retinal ganglion cell death, in vitro. Invest Ophthalmol Vis Sci. 2004;45(11):4049-59. doi:10.1167/iovs.04-0490.

60. Tezel G, Yang X, Yang J, Wax MB. Role of tumor necrosis factor receptor-1 in the death of retinal ganglion cells following optic nerve crush injury in mice. Brain Res. 2004:996(2):202-12

61. Fernandes KA, Harder JM, Fornarola LB, Freeman RS, Clark AF, Pang $\mathrm{IH}$, et al. JNK2 and JNK3 are major regulators of axonal injury-induced retinal ganglion cell death. Neurobiol Dis. 2012;46(2):393-401. doi:10.1016/j.nbd.2012.02.003.

62. Nguyen SM, Alexejun CN, Levin LA. Amplification of a reactive oxygen species signal in axotomized retinal ganglion cells. Antioxid Redox Signal. 2003;5(5):629-34. doi:10.1089/152308603770310293.

\section{Submit your next manuscript to BioMed Central and take full advantage of:}

- Convenient online submission

- Thorough peer review

- No space constraints or color figure charges

- Immediate publication on acceptance

- Inclusion in PubMed, CAS, Scopus and Google Scholar

- Research which is freely available for redistribution 